\title{
CDISC SEND Macroscopic Findings Test Code Terminology
}

National Cancer Institute

\section{Source}

National Cancer Institute. CDISC SEND Macroscopic Findings Test Code Terminology.

NCI Thesaurus. Code C89972.

The terminology that includes concepts relevant to the Clinical Data Interchange

Standards Consortium (CDISC) Standard for the Exchange of Non-clinical Data (SEND)

macroscopic findings test short names. 